\title{
Correction
}

\section{Correction: Ford et al., Engagement of the GABA to KCC2 Signaling Pathway Contributes to the Analgesic Effects of $\mathrm{A}_{3} \mathrm{AR}$ Agonists in Neuropathic Pain}

In the article "Engagement of the GABA to KCC2 Signaling Pathway Contributes to the Analgesic Effects of $\mathrm{A}_{3} \mathrm{AR}$ Agonists in Neuropathic Pain" by Amanda Ford, Annie Castonguay, Martin Cottet, Joshua W. Little, Zhoumou Chen, Ashley M. Symons-Liguori, Timothy Doyle, Terrance M. Egan, Todd W. Vanderah, Yves De Konnick, Dilip K. Tosh, Kenneth A. Jacobson, and Daniela Salvemini, which appeared on pages 6057-6067 of the April 15, 2015 issue, the tenth author's last name was incorrectly spelled. The corrected author line is: Amanda Ford, Annie Castonguay, Martin Cottet, Joshua W. Little, Zhoumou Chen, Ashley M. Symons-Liguori, Timothy Doyle, Terrance M. Egan, Todd W. Vanderah, Yves De Koninck, Dilip K. Tosh, Kenneth A. Jacobson, and Daniela Salvemini, which has been corrected in the online PDF version.

DOI: 10.1523/JNEUROSCI.4107-15.2015 